with a late systolic mitral murmur as the only abnormal sign is good, apart from the risk of bacterial endocarditis, which occurred in 5 cases. From a review of their own and other published cases, Allen et al. found no justification for the belief that ventricular ectopic beats are dangerous and no evidence that sudden death occurs in such patients, provided that care is taken to exclude those with ischaemic or myocardial heart disease.

1 Cuffer and Barbillon, Archives of General Medicine, 1887, 1, 131 and 301. 2 Griffith, J. P. C., American Fournal of the Medical Sciences, 1892, 104, 285. 3 Hall, J. N., American fournal of the Medical Sciences, 1903, 125, 663.

4 Leatham, A., Lancet, 1958, 2, 703.

5 Humphries, J. O., and McKusick, V. A., Progress in Cardiovascular Diseases, $1962,5,152$.

Diseases, 1962, 5, 152.

7 Jeresaty, R. M., Progress in Cardiovascular Diseases, 1973, 15, 623.

8 Allen, H., et al., British Heart fournal, 1974, 36, 525.

\section{Tube Transplants}

Disease affecting the capacity of the Fallopian tube to allow free passage of spermatozoa and ova accounts for about onequarter of all cases of infertility in women. The results of treatment of Fallopian tube damage are almost universally bad, though a very few surgeons claim pregnancy rates of up to $30 \%$ after reconstructive tuboplasty. These poor results reflect the fact that damage to the tubes is usually secondary to infection, which destroys both the musculature and the complex epithelial architecture. Even if patency is reestablished the environment for fertilization and properly timed transport of the blastocyst is rarely satisfactory. ${ }^{1}$

In the future one possibility ${ }^{2}$ for such patients might be homograft transplantation of tubes from healthy women, provided that technical and immunological problems can be overcome. Unlike most organs for which transplantation is employed there is a ready supply of donor tissue-women undergoing hysterectomy or sterilization frequently have entirely healthy tubes. If a graft is to succeed then adequate blood supply must be maintained. A major problem has been that the vessels of the human oviduct are very small. Cohen ${ }^{3}$ has reconstituted the blood supply of homograft tubes in the pig by using side-to-side anastomosis of the uterine artery and an ingenious end-to-side venous anastomosis with the vena cava. Though his efforts have been attended by a high incidence of thrombosis in the vessels of the graft, he has reported a viable, unrejected tube in one animal after 134 days, but there have been no pregnancies so far. The relevance of research in the pig to successful transplantation in women is, however, questionable in view of the remarkable ability of the pig to tolerate foreign tissues. Animal pregnancies have now been achieved after tubal autotransplantation, ${ }^{4}$ using a microsurgical technique and end-to-end vascular anastomosis. It appears that with careful handling of the fine vessels thrombosis need not be a major problem. Certainly a microsurgical technique causing very limited trauma minimizes any fibrotic reaction and the formation of peritubal adhesions and also achieves a satisfactory blood supply.

Homograft transplantation of the tube is, then, technically feasible, but the immunological status of the oviduct remains in doubt. There is some evidence ${ }^{56}$ that the ovary is a privileged site, but it is likely that in view of its rich lymphatic drainage the oviduct would be more readily rejected. Animal research in progress ${ }^{7}$ may help to decide the length of time the grafted tube will remain viable with or without immuno- suppressive therapy. There are several reasons for supposing that the immunological and logistic problems are not insuperable. Since so much potential donor tissue is readily available unusually close tissue typing could be obtained. Transplant operations could be performed when donor tissue is being removed at hysterectomy in an adjacent theatre, thus cutting the warm-ischaemia time of the graft to the minimum. Furthermore it is not essential for the graft to remain viable indefinitely after surgery provided that fertilization and secure implantation of the embryo occur fairly soon afterwards. Once pregnancy is established any disturbance which might occur as a result of rejection is likely to be negligible in view of the tiny bulk of transplanted tissue. Moreover limited immunosuppressive therapy need not be regarded as out of the question: there is good evidence, for example, that high doses of corticosteroids do not adversely affect human pregnancy, and indeed several babies have now been born to women who have received immunosuppressives of greater toxicity after renal transplantation. With careful selection of the appropriate drugs there should be little risk of fetal malformation-and, indeed, the striking progress in our knowledge of tissue rejection may soon minimize the need for present methods of immunosuppression.

Research into in-vitro fertilization is designed to help the same group of infertile patients, but homograft transplantation may prove to be more useful. Tubal transplants would be more acceptable to women, particularly as only one operative procedure would be required, and relatively few complicated laboratory investigations are needed. A technical disadvantage of in-vitro fertilization is that ovum pick up is likely to be difficult in many patients, since severe tubal damage is usually associated with considerable periovarian adhesions, which prevent good laparoscopic access. Furthermore, though invitro fertilization may result in a successful human pregnancy in the individual case, tubal transplantation could offer the childless woman a permanent cure of her tubal infertility.

\footnotetext{
1 Mastroianni, L., Scientific Foundations of Obstetrics and Gynaecology, ed. E. Phillip, M. Newton, and J. Barnes. London, Heinemann, 1970. 2 Jeffcoate, T. N. A., Principles of Gynaecology, 3rd edn. London,

3 Cohen, B., South African Medical fournal, 1974, 48, 162.

4 Winston, R. M. L., and Browne, J. C. M., Lancet, 1974, 2, 494.

Mattingly, R. F., et al., American fournal of Obstetrics and Gynecology, 1970, 108, 773 .

B Blanco, R., Proceedings of VIIIth World Congress of Fertility and Sterility, 1974, Buenos Aires. (in press).

7 Winston, R. M. L., Proceedings of VIIIth World Congress of Fertility and Sterility, 1974, Buenos Aires. (in press).
}

\section{A Fair Deal for Patients with Renal Failure}

Transplant surgeons in Britain are starved of kidneys-and many of those they do get are of poor quality and fail to function after transplantation. The extent of the problem and the reasons for the shortage are described at p. 251 in a memorandum from the British Transplantation Society, which puts forward some practical proposals for improving the supply of donor organs. These include changes in the law and a code of practice for transplant surgeons designed to dispel any remaining public anxieties about the subject.

Whenever such proposals are voiced there is opposition from those renal physicians who believe that dialysis, and especially home dialysis, offers patients a better chance of survival than does cadaver transplantation. No one can dispute, however, 